Article

\title{
Adaptive Droop Control for Microgrids Based on the Synergetic Control of Multi-Agent Systems
}

\author{
Zhiwen Yu *, Qian Ai, Xing He and Longjian Piao \\ School of Electronic Information and Electrical Engineering, Shanghai Jiaotong University, Dongchuan Road, \\ Shanghai 200240, China; aiqian@sjtu.edu.cn (Q.A.); hexing_hx@126.com (X.H.); longjianpiao@gmail.com (L.P.) \\ * Correspondence: yuzhiwen@sjtu.edu.com; Tel.: +86-21-34294584
}

Academic Editor: Josep M. Guerrero

Received: 25 September 2016; Accepted: 7 December 2016; Published: 15 December 2016

\begin{abstract}
In this paper, a distributed synergetic control based on multi-agent systems is proposed to solve the problems of frequency and voltage errors, system stability and power sharing accuracy in the traditional droop control of microgrids. Starting with power flow equations, we build the secondary-order dynamic model of DG, which consists of three parts: (1) active power allocation; (2) active power-frequency; and (3) reactive power-voltage droop control. Considering time-delays in communication networks, a leaderless synergetic control algorithm is proposed to allocate the active power in inverse proportion to the droop coefficient, and the synergetic control with a virtual leader is proposed to control the system frequency and voltage to keep at the expected value. Besides, the direct Lyapunov method is introduced to verify the globally asymptotical stability. Moreover, the impacts of communication disturbance are also discussed from the aspects of control precision and system stability. Finally, based on a test microgrid, numerous cases are designed as illustration, and the simulation results validate the proposed method.
\end{abstract}

Keywords: microgrid; adaptive droop control; multi-agent system; time-delays; globally asymptotical stability

\section{Introduction}

Distributed generations (DGs), especially renewable energy sources (RES), are drawing increasing attention around the world due to their advantages of lower energy consumption, high efficiency, economic and environmental benefits [1,2]. However, the output power of small-scale DGs, such as wind turbines, fuel cells, gas engines and energy storage, poses many challenges for electrical power systems, especially for distribution systems. Microgrids (MGs) are proposed to solve the interconnection problems of individual DGs [1-22].

A MG can work in both grid-connected and islanded modes. In normal operation, the MG connects to the main grid, where an inverter-based DG usually works in power mode in order to export the pre-set power to the main grid, and most system dynamics are dictated by the main grid due to the relatively small size of DGs [17]. In the event of disturbances, the MG disconnects from the main grid and operates in islanded mode. In this situation, it is important to continue to provide adequate power for the load, and DGs are responsible for maintaining the system frequency and voltage, and sharing the active and reactive power properly $[6,7,9,10]$. Proper controls with centralized or decentralized structures are necessary to maintain operations stable and economically efficient. Among them, distributed control is the most desirable option because the communication network in centralized control is complex and spans a large geographical area [3,5-13].

In an inverter-based MG, there is no synchronous generator, and the system inertia is very small. Based on the power flow of a transmission Adaptive Droop Control (AC) system with highly inductive impedance, the frequency/voltage droop control is applied so that parallel-connected DGs can allocate 
the active and reactive power in proportion to the rated value $[5-8,10]$, where the active power is mostly controlled by the frequency and the reactive power is mainly controlled by the amplitude voltage [5].

However, most previous works have shown that the droop parameters have a significant effect on the power sharing accuracy, small signal stability (SSS), and frequency and voltage drops [10-18]. In droop-controlled MG, a high gain frequency droop is required to ensure proper load sharing. Pogaku et al. investigated in [10] the SSS, including the controller, output filter and coupling inductor, and the results showed that a high gain frequency droop has a negative impact on SSS and decreases the system oscillation damping. Therefore, the energy management system of MG is designed after considering the SSS [11-13]. Some other works have emphasized power sharing accuracy. In [14], the original frequency and voltage are transformed into the virtual frame to decouple the relationship between active and reactive power completely, and the power sharing control in virtual frame is given. In [15], the virtual impedance is proposed to properly adjust the output impedances of DGs. However, the aforementioned controls need to know the network parameters and operation point at the beginning, and thus, they are not practical. In [16], the active power-voltage and reactive power-frequency droop control are proposed for resistive grids, but the active power sharing is poor. Since the power angle changes along with the frequency, the power angle-active power droop is proposed in [17] so that the frequency error is avoided. Meanwhile, auxiliary loop and other improved droop methods [14,16,17,21-24], such as adaptive droop control [14], arctan power-frequency droop [21] and virtual flux droop control [22], are introduced to improve the SSS and power sharing accuracy. However, the problems in traditional droop control are only partly solved in these previous works.

In traditional controls, the communication network is avoided, and each DG regulates its output according to the sampled data. However, the inter-communication network among DGs is necessary due to the requirements of the energy management system and protection of the MG. Therefore, the distributed control based on the spare-communication network can be used to solve the aforementioned problems. Recently, distributed strategies have been widely used in power systems [25-30]. Among them, multi-agent systems (MASs) are drawing increasingly attention because the requirements for a central controller and complex communication network are reduced. In a MAS, an agent, with self-organizing and self-learning ability, can work alone to reach some individual goals. However, it can only accomplish easy tasks because its ability to work, learn, process information and make decisions is limited. By organizing and coordinating all the agents, MASs can handle problems which are much more complicated and time-consuming, and have several advantages over traditional approaches, such as higher reliability and robustness of the control system. Recently, MASs have been widely used to develop complex systems and to achieve the objectives of distributed management, monitoring and control of microgrid [27-29].

In this paper, an improved synergetic control based on a MAS is proposed to design the droop parameters adaptively, where the MG is seen as a MAS, and the DG is considered as an agent. This paper makes the following contributions:

- Distributed synergetic control is used to design the droop parameters adaptively, in which each DG only requires the local and neighbor's information.

- The general synergetic control algorithm considering the time-delays in communication network is proposed to adjust the initial frequency $\omega_{0}$ and voltage $V_{0}$ in droop control adaptively, which are used to compensate the frequency and voltage drops, respectively. Therefore, the system frequency and voltage are always at the expected value.

- The improved control strategy can effectively reduce the effects of the disturbance on the control precision and stability of the communication.

- Under the proposed control, the MG system has the globally asymptotic stability which has been verified by the direct Lyapunov method. Therefore, the effect of droop coefficients on stability in traditional and improved controls has been eliminated. 
This paper is organized as follows: Section 2 discusses the dynamic model of the MAS-based MG based on power sharing of parallel-connected DGs. In Section 3, the adaptive droop control based on distributed synergetic method is presented, and the direct Lyapunov method is used to analyze the system stability. In Section 4, simulations based on a test MG are given to verify the adaptive droop control and the corresponding analysis and discussion are presented in Section 5. Section 6 concludes the paper.

\section{Dynamic Model of VSC-Based DG}

In a MG, most DGs connect to the power grid through voltage source converters (VSCs), and the typical structure is illustrated in Figure 1. The typical VSC is comprised of several parts, including the power-sharing controller (the droop controller), voltage and current controller, inverter and switching process, output filter, coupling inductance, and a primary source [9]. The details of each part are described in [10], where the input is considered fixed. Because the dynamics of voltage and current controllers are much faster than that of power controller, the combination of inverter, output filter, and primary sources can be seen as an ideal controllable voltage source, where the frequency and amplitude voltage are decided by the power controller [31].

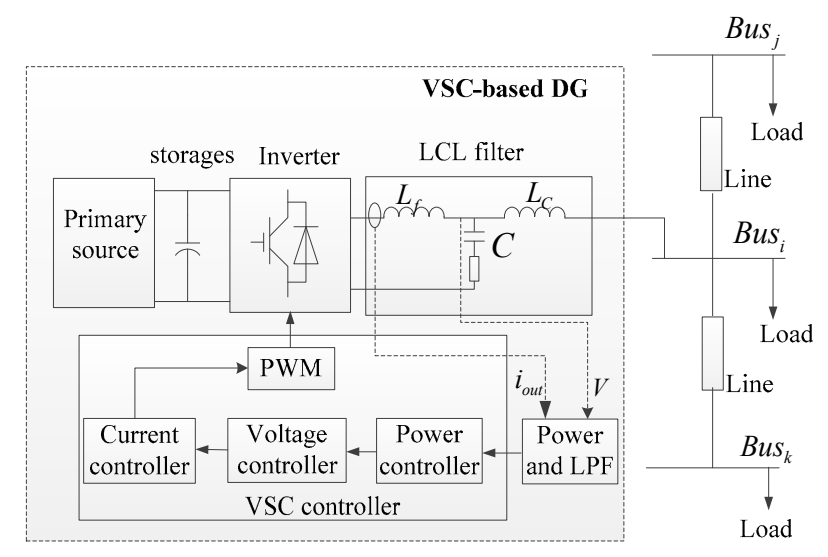

Figure 1. Typical structure of a VSC-based DG.

The power flow of the power grid is illustrated in Figure 2. By simplifying the basic power flow, we can obtain the relationship between power and voltage.

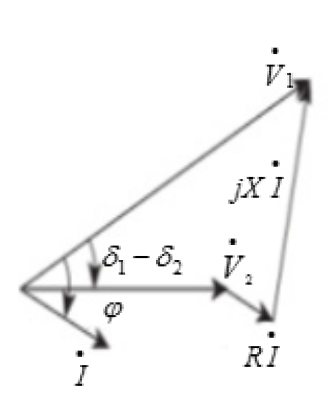

(a)

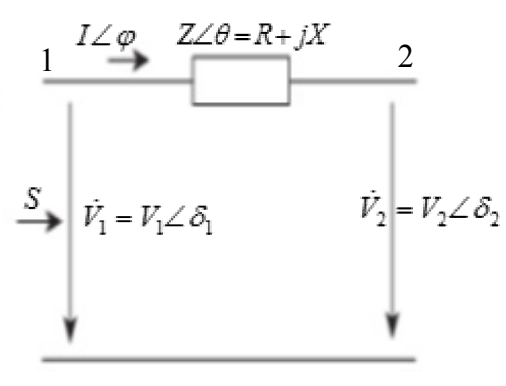

(b)

Figure 2. Power flow in MG. (a) Voltage vector; (b) power flow.

$$
\begin{gathered}
X P_{L}-R Q_{L}=V_{1} V_{2} \sin \left(\delta_{1}-\delta_{2}\right) \\
R P_{L}+X Q_{L}=V_{1}^{2}-V_{1} V_{2} \cos \left(\delta_{1}-\delta_{2}\right)
\end{gathered}
$$


In high voltage AC transmission line, $R$ can be neglected, and the phase difference is very small, i.e., $\sin \delta \approx \delta$ and $\cos \delta \approx 1$. Then, the power flow can be simplified as follows:

$$
\begin{gathered}
P_{L}=\frac{V_{1} V_{2}}{X} \sin \left(\delta_{1}-\delta_{2}\right) \approx \frac{V_{1} V_{2}}{X} \Delta \delta \\
Q_{L}=\frac{V_{1}}{X}\left(V_{1}-V_{2} \cos \left(\delta_{1}-\delta_{2}\right)\right) \approx \frac{V_{1}}{X} \Delta V
\end{gathered}
$$

where $\Delta \delta=\delta_{1}-\delta_{2}$ and $\Delta V=V_{1}-V_{2}$.

Therefore, the active and reactive power of DG can be regulated by drooping the system frequency and the node amplitude voltage, respectively:

$$
\left\{\begin{array}{l}
\omega_{i}=\omega_{0 i}-m_{i} P_{i} \\
V_{d i}^{*}=V_{0 i}-n_{i} Q_{i} \\
V_{q i}^{*}=0
\end{array}\right.
$$

where the subscript of $i$ is the sequence of DG in the MG.

Equation (5) expresses the traditional droop control, and Figure 3 illustrates the control diagram, where LPF is the low pass filter, which is used to prevent the switch disturbance and $\omega_{c}$ is the cut-off frequency.

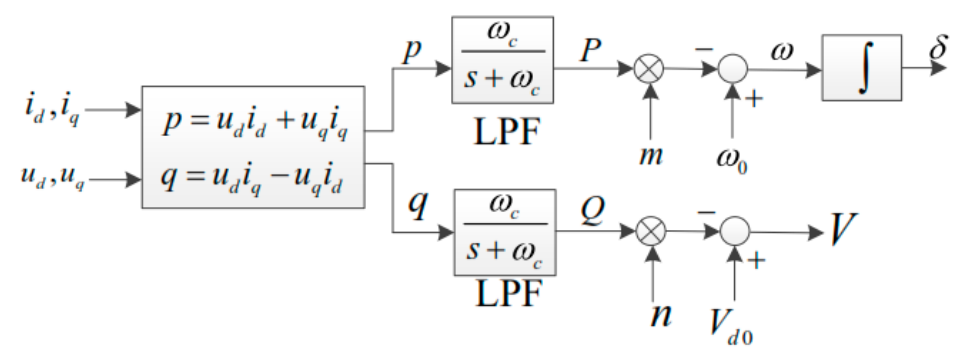

Figure 3. Control diagram of the traditional droop.

In traditional droop control, $\omega_{0}$ and $V_{0}$ with a fixed value are designed to keep the system frequency and voltage in a prospective range. Therefore, these two parameters are usually neglected in SSS, and improved controls are usually to design the droop coefficients [21] or use the auxiliary control $[16,17]$ to improve the system stability and power sharing accuracy. However, the problems of system stability, frequency and voltage deviation also exist. In response to these problems, this paper aims to design $\omega_{0}$ and $V_{0}$.

By differentiating the traditional droop control in Equation (5), we can obtain:

$$
\begin{gathered}
\dot{\omega}_{i}=\dot{\omega}_{0 i}-m_{i} \dot{P}_{i} \equiv x_{\omega i} \\
\dot{V}_{d i}=\dot{V}_{0 i}-n_{i} \dot{Q}_{i} \equiv x_{v i}
\end{gathered}
$$

Equations (6) and (7) show the first-order dynamic model of DG. The first-order system is a time-delay control system, and only the differential value can be controlled directly. In this paper, a secondary-order model is used by expanding the first-order model in Equations (6) and (7):

$$
\begin{aligned}
& \dot{x}_{\omega i}=u_{c \omega i} \\
& \dot{x}_{v i}=u_{c v i}
\end{aligned}
$$

By properly designing the auxiliary variable of $u_{c \omega i}$ and $u_{c v i}$, the MG can work at the expected frequency and voltage. Meanwhile, it should be noted that once the auxiliary control is applied to 
the frequency control, the active power of DG must be allocated in inverse proportion to the droop coefficients, i.e.,:

$$
m_{1} P_{1}=m_{2} P_{2}=\cdots=m_{n} P_{n}
$$

In power controller, the droop coefficients are designed as a constant according to the operation range of frequency and DG capacity, where mi are set based on the rated active power of DGs $P_{N i}$ [10], which is equivalent to $\frac{P_{1}}{P_{N 1}}=\frac{P_{2}}{P_{N 2}}=\cdots=\frac{P_{n}}{P_{N n}}$, where $P_{\mathrm{N}}$ is the rated active power.

Then, the secondary-order model of active power allocation can be derived by differentiating Equation (10) and using the same way in Equation (8):

$$
\left\{\begin{array}{l}
m_{i} \dot{P}_{i}=x_{P i} \\
\dot{x}_{P i}=u_{c P i}
\end{array}\right.
$$

Therefore, the active power can be allocated in inverse proportion to the droop coefficients by designing $u_{c P}$. Therefore, the combination of Equations (6)-(9) and (11) forms the whole dynamic model of an islanded MG. The next section describes the design of the synergetic control based on the above models.

\section{Adaptive Droop Control Based on MAS}

In islanded MG, the DG is considered as an agent, which has the ability to regulate its work state by sampling the system frequency and node voltage. However, the DG cannot finish the missions of the whole system due to the lack of system information. For example, the traditional droop control is a full self-management control, where the DG only needs its sampled data to regulate the output power, but the system may be unstable [10]. Therefore, this paper tries to propose a synergetic control to design the droop parameters adaptively based on the distributed communication network. In this synergetic control, each DG only needs to send its power and voltage to the neighbors and receive the same information from them. Based on these information, the DG regulates the droop parameters to export an expected power to the grid which is unknown at first, so that the MG can work at an expectant state. In this section, firstly the communication network is modelled by diagraph theorem.

\subsection{Graph Theorem}

In a MAS, the spare communication network is usually expressed by a digraph $[25,29]$. In the communication network, an agent is seen as a node, and the edge between two DGs is considered as a link. In this paper, a test MG illustrated in Figure 4 and the communication network without leaders in Figure 5 is studied. A digraph is usually depicted as $G=(V, \varepsilon, A)$ with a non-empty node finite set $\boldsymbol{V}=\left\{v_{1}, v_{2}, \cdots, v_{N}\right\}$, a set of edges $\varepsilon \in(V \times V)$ that is the Cartesian product of $\boldsymbol{V}$, and the associated adjacency matrix $A=\left[a_{i j}\right] \in R^{N \times N}$. In this paper, the communication network is assumed to be time-invariant, and $A$ is constant. In $G$, the edge $\left(v_{j}, v_{i}\right)$ means that node $i$ receives the information from node $j$, and $\left(v_{i}, v_{i}\right)$ denotes the edge from node $i$ to itself, which is usually neglected. $a_{i j}$ is the weight of edge $\left(v_{j}, v_{i}\right)$, and $a_{i j}>0$, if $\left(v_{j}, v_{i}\right) \in \varepsilon$, which means that node $j$ is a neighbor of node $i$; otherwise $a_{i j}=0$. In a diagraph, the set of neighbors of node $i$ is denoted as $N_{i}=\left\{v_{j} \mid\left(v_{j}, v_{i}\right) \in \varepsilon\right\}$. In the MG, because DGs exchange information through a communication bus, the non-directed diagraph is considered, which means that node $i$ not only receives the information from node $j$, and also sends the corresponding information to node $j$ at the same time. Usually, the Laplacian matrix of the digraph is used to express the communication relation defined as $L=\left[l_{i j}\right] \epsilon R^{n \times n}$, where $l_{i j}=-a_{i j}$ if $i \neq j$, and $l_{i i}=0$. In this paper, the weight of each edge is 1 , the Laplacian matrix of the test MG is:

$$
L=\left[\begin{array}{crrr}
0 & -1 & 0 & -1 \\
-1 & 0 & -1 & 0 \\
0 & -1 & 0 & -1 \\
-1 & 0 & -1 & 0
\end{array}\right]
$$




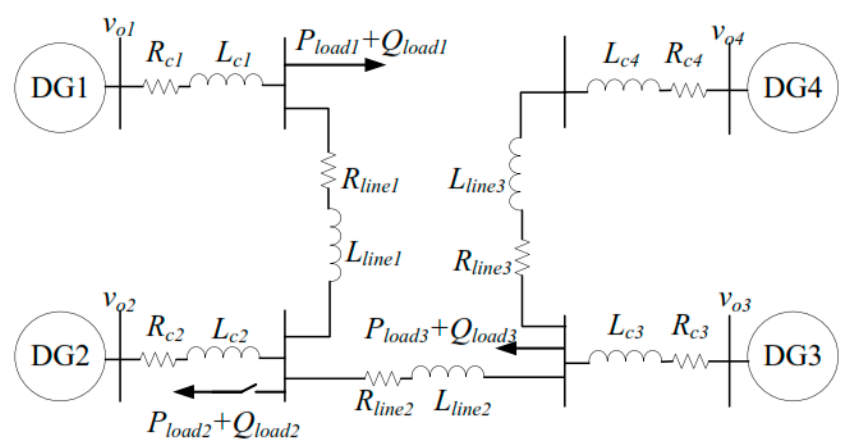

Figure 4. Test MG system.

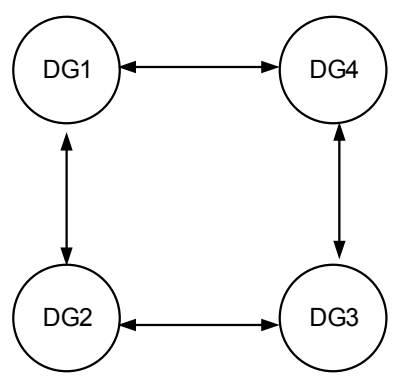

Figure 5. Communication network.

\subsection{Active Power Control}

In an islanded MG, the active power of a DG is allocated in inverse proportion to the droop coefficient so that the MG can work in a large range of loads due to the small capacity. Therefore, the active power allocation is designed first. To achieve the precise allocation of active power, we assume that the DG can communicate with the neighbors through diagraph G. Because the active power of a DG changes along with the loads, the synergetic control without leaders is adopted to design the auxiliary variable in Equation (11). The auxiliary control variable considering time-delays in communication is discussed in [27]. Here, the general control algorithm considering time-delays is provided to obtain the auxiliary variable:

$$
\begin{gathered}
u_{c P i}=u_{c P \alpha i}+u_{c P \beta i} \\
u_{c P \alpha i}=-k_{P 1} \sum_{j=1, j \neq i}^{n} a_{i j} f\left(\Delta m P_{i j}\right) \\
u_{c P \beta i}=\sum_{i=1, i \neq j}^{n} a_{i j} \operatorname{sign}\left(x_{P j i}\right)\left|x_{P j i}\right|^{k_{P 2}} \\
\Delta m P_{i j}=m_{i} P_{i}(t)-m_{j} P_{j}\left(t-t_{d}\right) \\
\mathrm{x}_{P j i}=\mathrm{x}_{P j}\left(t-t_{d}\right)-\mathrm{x}_{P i}(t) \\
f(x)>0, \quad x>0 ; \\
f(x)=0, \quad x=0 ; \\
f(x)<0, \quad x<0 . \\
\operatorname{sign}(x)=\left[\begin{array}{c}
1, \text { when } x \geq 0 \\
-1, \text { when } x \leq 0
\end{array}\right.
\end{gathered}
$$


where $u_{c P \alpha i}$ and $u_{c P \beta i}$ are two individual parts of $u_{c P i}$, and the details are given in Equations (13a) and (13b), respectively. In Equation (13), $u_{c P \alpha i}$ is used to directly control $\left(m_{i} P_{i}\right)$ in Equation (13c) to be the same, and $u_{c P \beta i}$ is used to control the differential of $\left(m_{i} P_{i}\right)$ to be the same. $k_{P 1}$ is non-negative.

The combination of Equations (11) and (13) forms the differential-algebraic equations (DAEs) of the active power allocation in an islanded MG. By setting all the differentials be zero, the solutions of the DAEs can be obtained:

$$
\begin{aligned}
& m_{i} P_{i}(t)=m_{j} P_{j}\left(t-t_{d}\right) \\
& m_{i} \dot{P}_{i}(t)=m_{j} \dot{P}_{j}\left(t-t_{d}\right)
\end{aligned}
$$

When the system works at the balance point, $u_{c P i}$ in Equation (13) is zero. Then, Equation (11) can be rewritten as:

$$
m_{i} \dot{P}_{i}(t)=m_{j} \dot{P}_{j}\left(t-t_{d}\right)=0
$$

This means that the active power of each DG is constant when the MG works in a stable state. However, we cannot come to this conclusion just by using the traditional first-order model in $[27,28]$. Then, combined with the analysis results in Equations (14) and (16), we can obtain that the equilibrium points of the system mean that the active power of each DG is allocated in inverse proportion to the droop coefficients, and the errors in each DG is 0 when the system works at the stable state. Furthermore, the system stability needs to be analyzed. In this paper, the direct Lyapunov method is used to show the globally asymptotic stability.

In a control system, the behavior of a system about its equilibrium point can be investigated by using Lyapunov theorem [31,32]. Lyapunov's stability theorem allows us to verify the stability of the MG system by analyzing an energy function $V(x)$, also called as the Lyapunov function. According to the direct Lyapunov method, the system has the globally asymptotical stability when the following four conditions about $V(x)$ are satisfied:

(1) $\quad V(0)=0$;

(2) $V(x)>0$, for all $x \neq 0$;

(3) $V(x) \rightarrow \infty$ as $\|x\| \rightarrow \infty$;

(4) $\dot{V}(x)<0$ for all $x \neq 0$.

To analyze the stability of the active power control in Equation (13), the following energy function is considered:

$$
V(x)=\frac{1}{2} \sum_{i=1}^{n} x_{P i}^{2}+\frac{1}{2} \sum_{i=1}^{n} \sum_{j=1, j \neq i}^{n} k_{P 1} a_{i j} F\left(\Delta m P_{i j}\right)
$$

where $F(x)$ is the integral of $f(x)$, i.e., $f(x)=\frac{d F(x)}{d t}$.

According to the characteristics of the sub-functions in Equation (17), we know that the first three conditions in Lyapunov theorem are always satisfied. Then, only the last one should be considered.

By differentiating the energy function, we can obtain:

$$
\dot{V}(x)=\sum_{i=1}^{n} x_{P i} u_{c P i}+\frac{1}{2} \sum_{i=1}^{n} \sum_{j=1, j \neq i}^{n} k_{P 1} a_{i j} f\left(\Delta m P_{i j}\right)(m \dot{P})_{i j}
$$

where $(m \dot{P})_{i j}=m_{i} \dot{P}_{i}(t)-m_{j} \dot{P}_{j}\left(t-t_{d}\right)$.

Then, adding the synergetic control in Equation (13) into it, yields:

$$
\dot{V}(x)=\sum_{i=1}^{n} a_{i j} x_{P i} \sum_{j=1, j \neq i}^{n}\left(-k_{P 1} f\left(\Delta m P_{i j}\right)+\operatorname{sign}\left(x_{P j i}\right)\left|x_{P j i}\right|^{k_{P 2}}\right)+\frac{1}{2} \sum_{i=1}^{n} \sum_{j=1, j \neq i}^{n} k_{P 1} a_{i j} f\left(\Delta m P_{i j}\right) x_{P i j}
$$


For the first and third part in Equation (19), the following equation is satisfied:

$$
\sum_{i=1}^{n} x_{P i} \sum_{j=1, j \neq i}^{n} k_{P 1} a_{i j} f\left(\Delta m P_{i j}\right)=\frac{1}{2} \sum_{i=1}^{n} \sum_{j=1, j \neq i}^{n} k_{P 1} a_{i j} f\left(\Delta m P_{i j}\right) x_{P i j}
$$

Thus, $\dot{V}(x)$ can be simplified as follows after adding Equation (20) into Equation (19):

$$
\dot{V}(x)=\frac{1}{2} \sum_{i=1}^{n} \sum_{j=1, j \neq i}^{n} a_{i j}\left(x_{P i}(t)-x_{P j}\left(t-t_{d}\right)\right) \operatorname{sign}\left(x_{P j}\left(t-t_{d}\right)-x_{P i}(t)\right)\left|x_{P j}\left(t-t_{d}\right)-x_{P i}(t)\right|^{k_{P 2}}
$$

By analyzing the characteristics in Equation (21), we know that $\dot{V}(x)<0$ for all $x \neq 0$. Therefore, the Lyapunov theorem conditions are always satisfied, and the MG has globally asymptotic stability under the synergetic control in Equation (13) in spite of the time-delays in communication. However, in the traditional control method, the time-delays have a negative impact on the system stability, and the report of synergetic control with time-delays is small. Especially, the previous works mostly focus on seeking the maximum time-delays in the traditional control so that the system can work at the stable state [33].

\subsection{Active Power-Frequency Droop Control}

In traditional droop control, the system frequency is varied along with the loads due to the constant value of $\omega_{0 i}$. In power systems, the expected frequency is the rated value, which is known at first and can be considered as the virtual leader in frequency control. The communication network with a virtual leader is illustrated in Figure 6, in which the virtual leader is the agent with the target frequency. Generally, the virtual leader is the MG central controller (MGCC). Similarly, taking the time-delays into consideration, $u_{c \omega i}$ is obtained by Equation (22) based on its own and the received information with time-delays from the neighbors.

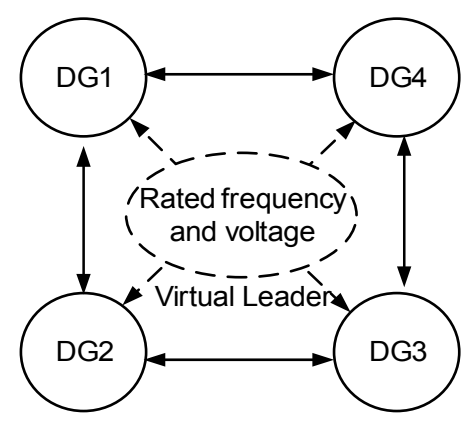

Figure 6. Diagraph with a virtual leader.

$$
\begin{gathered}
u_{c \omega i}=u_{c \omega \alpha i}+u_{c \omega \beta i}+u_{c \omega \gamma i} \\
u_{c \omega \alpha i}=-k_{\omega 1} \sum_{j=1, j \neq i}^{n} a_{i j} g\left(\omega_{i j}\right) \\
u_{c \omega \beta i}=\sum_{i=1, i \neq j}^{n} a_{i j} \operatorname{sign}\left(x_{\omega j i}\right)\left|x_{\omega j i}\right|^{k_{\omega 2}} \\
u_{c \omega \gamma i}=k_{\omega 3}\left[-k_{\omega 1} f\left(\omega_{i L}\right)+\operatorname{sign}\left(x_{\omega L i}\right)\left|x_{\omega L i}\right|^{k_{\omega 2}}\right] \\
\omega_{i j}=\omega_{i}(t)-\omega_{j}\left(t-t_{d}\right) \\
\omega_{i L}=\omega_{i}-\omega_{L}
\end{gathered}
$$




$$
\begin{gathered}
x_{\omega j i}=x_{\omega j}\left(t-t_{d}\right)-x_{\omega i}(t) \\
x_{\omega L i}=x_{\omega L}-x_{\omega i} \\
\left\{\begin{array}{c}
g(x)>0, \quad x>0 \\
g(x)=0, \quad x=0 \\
g(x)<0, \quad x<0 .
\end{array}\right.
\end{gathered}
$$

where the subscript of $L$ means the virtual leader; $u_{c \omega \alpha i}, u_{c \omega \beta i}$ and $u_{c \omega \gamma i}$ are three individual parts of $u_{c \omega i}$, which are given from Equations (22a) to (22c), respectively. In Equation (22), $u_{c \omega a i}$ is to directly control the output frequency of each DG to be the same; $u_{c \omega \beta i}$ is used to control the differential frequency to be the same, and $u_{c \omega \gamma i}$ is used to control the front two parts to synchronize to the virtual leader with the rated frequency. $k_{\omega 1}$ and $k_{\omega 3}$ are non-negative, i.e., $k_{\omega 1}, k_{\omega 3} \geq 0$. Because the value of the virtual leader is set as constant at the beginning, the time-delays from the virtual leader to DG are considered as zero.

Similarly, the solution of DAEs consisted by Equations (6), (8) and (22) can be obtained through making all the differential be zero, i.e.,:

$$
\begin{gathered}
\omega_{i}(t)=\omega_{j}\left(t-t_{d}\right)=\omega_{N} \\
\dot{\omega}_{i}(t)=\dot{\omega}_{j}\left(t-t_{d}\right)=0
\end{gathered}
$$

which means that the frequency of each DG can be controlled to be the same with the virtual leader, and the fluctuation is near to zero.

Meanwhile, the following energy function is considered to verify the stability:

$$
V(x)=\frac{1}{2} \sum_{i=1}^{n}\left(x_{\omega i L}\right)^{2}+\frac{1}{2} \sum_{i=1}^{n} \sum_{j=1, j \neq i}^{n} k_{\omega 1} a_{i j} G\left(\omega_{i j}\right)+\sum_{i=1}^{n} k_{\omega 1} k_{\omega 3} G\left(\omega_{i L}\right)
$$

where $G(x)$ is the integral of $g(x)$, i.e., $g(x)=\frac{d G(x)}{d t}$.

Obviously, the first three conditions in Lyapunov theorem are always satisfied. By differentiating Equation (25) and adding the synergetic control equation into it, we can obtain:

$$
\dot{V}(x)=\sum_{i=1}^{n} x_{\omega i L}\left(u_{c \omega \alpha i}+u_{c \omega \beta i}+u_{c \omega \gamma i}\right)+\sum_{i=1}^{n} k_{\omega 1} k_{\omega 3} g\left(\omega_{i L}\right) \omega_{i L}+\frac{1}{2} \sum_{i=1}^{n} \sum_{j=1, j \neq i}^{n} k_{\omega 1} a_{i j} g\left(\omega_{i j}\right) \dot{\omega}_{i j}
$$

Suppose that $\hat{x}_{\omega i}=x_{\omega i}-x_{\omega L}$, we can obtain:

$$
x_{\omega i}(t)-x_{\omega j}\left(t-t_{d}\right)=\hat{x}_{\omega i}-\hat{x}_{\omega j}\left(t-t_{d}\right)
$$

Then, adding Equations (22) and (27) into Equation (25), and utilizing the analysis results in Equation (20), $\dot{V}(x)$ can be simplified as:

$$
\dot{V}(x)=\sum_{i=1}^{n} \hat{x}_{\omega i} \sum_{j=1, j \neq i}^{n} a_{i j} \operatorname{sign}\left(\hat{x}_{\omega j i}\right)\left|\hat{x}_{\omega j i}\right|^{k_{\omega 2}}+k_{\omega 3} \sum_{i=1}^{n} \hat{x}_{\omega i} \operatorname{sign}\left(-\hat{x}_{\omega i}\right)\left|-\hat{x}_{\omega i}\right|^{k_{\omega 2}}
$$

According to the analysis results in Equation (21), we know that the conditions in the Lyapunov theorem are always satisfied, which means that the islanded MG has globally asymptotic stability under the synergetic active power-frequency droop control despite the impacts of communication time-delays. 
Therefore, combining with the agent model in Equations (6) and (8), the adaptive droop control and the synergetic control in Equation (22), the active power-frequency droop control can be written as follows:

$$
\omega_{o i}=\int\left(m_{i} \dot{P}_{i}+\int u_{c \omega i} d t\right) d t+\omega_{o i 0}
$$

where $\omega_{o i 0}$ is the initial value of $\omega_{o i}$ in the traditional droop control.

Because the active power allocation of DG is in inverse proportion to the droop coefficients, the active power in Equation (29) is no more than the output active power of DG. Then, by combining with the analysis result of the active power allocation in Equation (13) and the traditional droop control in Equation (5), the proposed active power-frequency droop control is:

$$
\omega_{i}=\int\left(\int u_{c P i} d t+\int u_{c \omega i} d t\right) d t+\omega_{o i 0}-m_{i} P_{i}
$$

According to the above control equation, the block diagram of the adaptive active power-frequency control is illustrated in Figure 7.

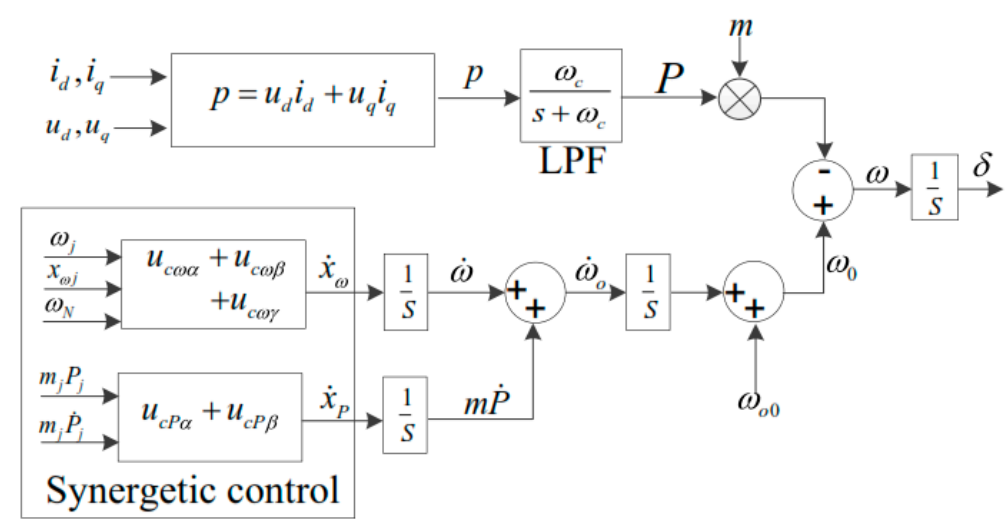

Figure 7. Diagram of the adaptive frequency droop control.

\subsection{Reactive Power-Voltage Droop Control}

In power systems, the reactive power of a VSC-based DG does not consume the primary source, and its allocation does not satisfy the characteristics of active power allocation because the voltage at each node is not the same. Meanwhile, we only consider the amplitude voltage, and the reactive power is allocated according to the power flow. Like the system frequency control, the expected voltage is known at the beginning, which can be considered as the virtual leader in voltage control. Then, the reactive power-voltage droop control can be designed likely with the active power-frequency droop control, and the auxiliary variable $u_{c v i}$ is chosen as follows:

$$
\begin{gathered}
u_{c v}=u_{c v \alpha i}+u_{c v \beta i}+u_{c v \gamma i} \\
u_{c v \alpha i}=-k_{v 1} \sum_{j=1, j \neq i}^{n} a_{i j}, g\left(V_{d i j}\right) \\
u_{c v \beta i}=\sum_{i=1, i \neq j}^{n} a_{i j} \operatorname{sign}\left(x_{v j i}\right)\left|x_{v j i}\right|^{k_{v 2}} \\
u_{c v \gamma i}=k_{v 3}\left[-k_{v 1} g\left(V_{d L i}\right)+\operatorname{sign}\left(x_{v L i}\right)\left|x_{v L i}\right|^{k_{v 2}}\right] \\
V_{d i j}=V_{d i}(t)-V_{d j}\left(t-t_{d}\right) \\
x_{v j i}=x_{v j}\left(t-t_{d}\right)-x_{v i}(t)
\end{gathered}
$$


where $u_{c v \alpha i}, u_{c v \beta i}$ and $u_{c v \gamma i}$ are three individual parts of $u_{c v i}$, that are given from Equations (31a) to (31c), respectively. $u_{c v \alpha i}$ is used to directly control the output voltage of each DG to be the same; $u_{c v \beta i}$ is used to control the differential voltage to be the same, and $u_{c v \gamma i}$ is used to control the front two parts to synchronize to the virtual leader with the expected voltage. $k_{v 1}$ and $k_{v 3}$ are non-negative, i.e., $k_{v 1}, k_{v 3} \geq 0$. Because the value of the virtual leader is set as constant at the beginning, the time-delays from the virtual leader to DG are considered as zero.

According to the analysis in active power-frequency droop control, the equilibrium point of the control is the purpose of the voltage droop control. Meanwhile, the MG is globally asymptotically stable under the synergetic control.

Therefore, by combining all equations of voltage control in Equations (7) and (9), the proposed reactive power-voltage control in Equation (31), the adaptive voltage control is:

$$
V_{i}=\int\left(n_{i} \dot{Q}_{i}+\int u_{c v i} d t\right) d t+V_{o i 0}-n_{i} Q_{i}
$$

where $V_{o i 0}$ is the initial value of $V_{o i}$ in traditional droop control.

Correspondingly, the block diagram of the adaptive reactive power-voltage droop control is illustrated in Figure 8.

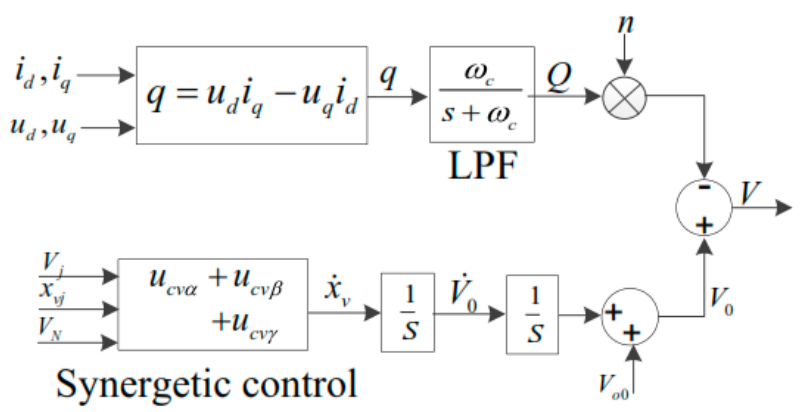

Figure 8. Diagram of adaptive voltage droop control.

\subsection{Performance with Disturbance in Communication Network}

In practical islanded MGs, the noise may have a negative effect on the traditional distributed control, such as the disturbances in communication network. Consequently, the control results may be not perfect and the system may be unstable. However, the proposed synergetic control also has a good performance with disturbances on communication network.

Suppose that $\delta_{x j}$ and $\delta_{x \omega j}$ are the disturbances of the communication network in $\omega_{j}$ and $x_{\omega j}$, respectively. Then, adding the disturbances to Equations (22d) and (22e), we can obtain:

$$
\begin{gathered}
\hat{\omega}_{i j}=\omega_{i}(t)-\left(\omega_{j}\left(t-t_{d}\right)+\delta_{\omega j}\right) \\
\hat{x}_{\omega j i}=\left(x_{\omega j}\left(t-t_{d}\right)+\delta_{x \omega j}\right)-x_{\omega i}(t)
\end{gathered}
$$

Similarly, the equilibrium point of the system can be obtained by setting all the differentials to be zero. Based on Equations (8), (22a)-(22c), (33) and (34), we can obtain:

$$
\begin{aligned}
& \omega_{i}(t)=\omega_{j}\left(t-t_{d}\right)+\delta_{\omega j}=\omega_{N} \\
& x_{\omega i}(t)=x_{\omega j}\left(t-t_{d}\right)+\delta_{x \omega j}=0
\end{aligned}
$$

The above two equations show that the frequency of DG can be regulated to be the same as the virtual leader and the differential is zero despite the impacts of disturbance in the communication network. 
Furthermore, we can also reach the conclusion that the MG has globally asymptotic stability when replacing $\omega_{i j}$ with $\hat{\omega}_{i j}$ in Equation (25). Therefore, the proposed control method has good performance, despite the disturbance in the communication networks.

\section{Simulation and Results}

In this section, a test MG illustrated in Figure 4 [29] is used to verify the proposed control, and the parameters are given in Table 1.

Table 1. Parameters of the MG system.

\begin{tabular}{|c|c|c|c|c|}
\hline \multirow{2}{*}{ DGs } & \multicolumn{2}{|c|}{$R_{c 1}=R_{c 2}=R_{c 3}=R_{c 4}$} & \multicolumn{2}{|c|}{$L_{c 1}=L_{c 2}=L_{c 3}=L_{c 4}$} \\
\hline & \multicolumn{2}{|c|}{$0.2 \Omega$} & \multicolumn{2}{|c|}{$1 \mathrm{mH}$} \\
\hline \multirow{2}{*}{ Lines } & \multicolumn{2}{|c|}{ Line $_{1}$ and Line 3} & \multicolumn{2}{|c|}{ Line $_{2}$} \\
\hline & $\begin{array}{c}R_{\text {Line } 1}=R_{\text {Line } 3} \\
0.23 \Omega\end{array}$ & $\begin{array}{c}L_{\text {Line } 1}=L_{\text {Line } 3} \\
0.318 \mathrm{mH}\end{array}$ & $\begin{array}{l}R_{\text {Line } 2} \\
0.35 \Omega\end{array}$ & $\begin{array}{c}L_{\text {Line } 2} \\
1.847 \mathrm{mH}\end{array}$ \\
\hline \multirow{4}{*}{ Loads } & \multicolumn{2}{|c|}{ Load $_{1}$} & \multicolumn{2}{|c|}{$\mathrm{Load}_{3}$} \\
\hline & $\begin{array}{c}\mathrm{P}_{1}(\mathrm{~kW}) \\
36\end{array}$ & $\begin{array}{c}\mathrm{Q}_{1}(\mathrm{kVar}) \\
36\end{array}$ & $\begin{array}{c}\mathrm{P}_{3}(\mathrm{~kW}) \\
45.9\end{array}$ & $\begin{array}{c}\mathrm{Q}_{3}(\mathrm{kVar}) \\
22.8\end{array}$ \\
\hline & \multicolumn{2}{|c|}{ Load $_{2}$} & & \\
\hline & $\begin{array}{c}\mathrm{P}_{2}(\mathrm{~kW}) \\
36\end{array}$ & $\begin{array}{c}\mathrm{Q}_{2}(\mathrm{kVar}) \\
36\end{array}$ & & \\
\hline
\end{tabular}

The rated power of DG1, DG2, DG3 and DG4 is $100 \mathrm{kVA}, 100 \mathrm{kVA}, 75 \mathrm{kVA}$ and $75 \mathrm{kVA}$, respectively. The expected voltage and frequency in the virtual leader are set as the rated, where the voltage amplitude is $311 \mathrm{~V}$ (maximum value) and the system frequency is $50 \mathrm{~Hz}$.

The control functions $f(x)$ and $g(x)$ must be chosen to satisfy the constraints in Equations (13e) and (22h). In this paper, we choose the following equation:

$$
f(x)=g(x)=\frac{2 x}{1+x^{2}}
$$

Consequently, $F(x)$ and $G(x)$ are:

$$
F(x)=G(x)=\operatorname{Ln}\left(1+x^{2}\right)
$$

It should be noted that other functions meeting the constraints in Equation (13e) can be adopted in the synergetic control, such as $f(x)=x^{k}$ when $k$ is odd.

To verify the effectiveness of the proposed control, simulations of the traditional droop control are also done. The droop parameters and control gains in synergetic control are given in Table 2 . The simulations and the results are done in EMTP and Matlab, respectively. Three cases are simulated to verify the effectiveness of the proposed control strategy. 
Table 2. Droop parameters and synergetic control gains.

\begin{tabular}{|c|c|c|c|c|}
\hline \multirow{4}{*}{$\begin{array}{l}\text { Primary } \\
\text { Control }\end{array}$} & $\mathrm{m}_{\mathrm{P} 1}=\mathrm{m}_{\mathrm{P} 2}$ & $\mathrm{n}_{\mathrm{Q} 1}=\mathrm{n}_{\mathrm{Q} 2}$ & $\mathrm{~m}_{\mathrm{P} 3}=\mathrm{m}_{\mathrm{P} 4}$ & $\mathrm{n}_{\mathrm{Q} 3}=\mathrm{n}_{\mathrm{Q} 4}$ \\
\hline & 0.000094 & 0.0013 & 0.000125 & 0.0015 \\
\hline & \multicolumn{2}{|c|}{$V_{o i}$} & \multicolumn{2}{|c|}{$\omega_{o i}$} \\
\hline & \multicolumn{2}{|c|}{$330 \mathrm{~V}$} & \multicolumn{2}{|c|}{$325.3 \mathrm{rad} / \mathrm{s}$} \\
\hline \multirow{3}{*}{ Control Gains } & Frequency & $\begin{array}{c}k_{\omega 1} \\
50\end{array}$ & $\begin{array}{l}k_{\omega 2} \\
0.8\end{array}$ & $\begin{array}{l}k_{\omega 3} \\
800\end{array}$ \\
\hline & Voltage & $\begin{array}{l}k_{v 1} \\
150\end{array}$ & $\begin{array}{l}k_{v 2} \\
0.8\end{array}$ & $\begin{array}{c}k_{v 3} \\
3\end{array}$ \\
\hline & Active power & $\begin{array}{l}k_{P 1} \\
500\end{array}$ & $\begin{array}{c}k_{P 2} \\
0.8\end{array}$ & \\
\hline
\end{tabular}

\subsection{Case Study I: Simulation without Time-Delays and Disturbance}

In this case, simulations without time-delays and disturbance in the communication network are used to show the performance of the proposed control strategy, and the comparison between the adaptive droop control and the traditional method is analyzed. The whole simulation time is $4 \mathrm{~s}$, and Load $_{2}$ connects to the grid at $t=2 \mathrm{~s}$. Figures 9 and 10 depicts the results of the proposed control and the traditional control, respectively.

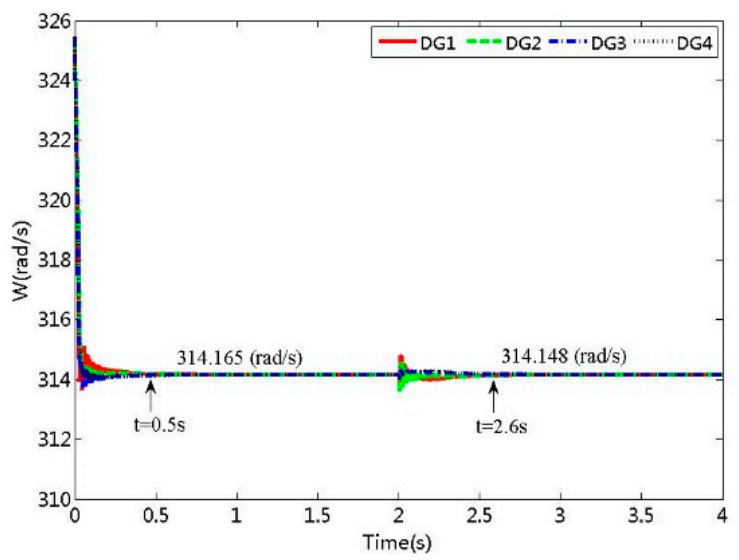

(a)

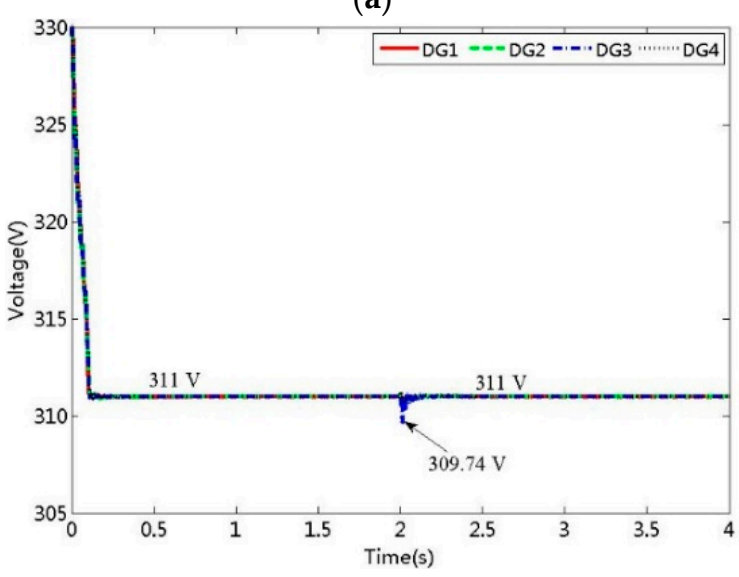

(c)

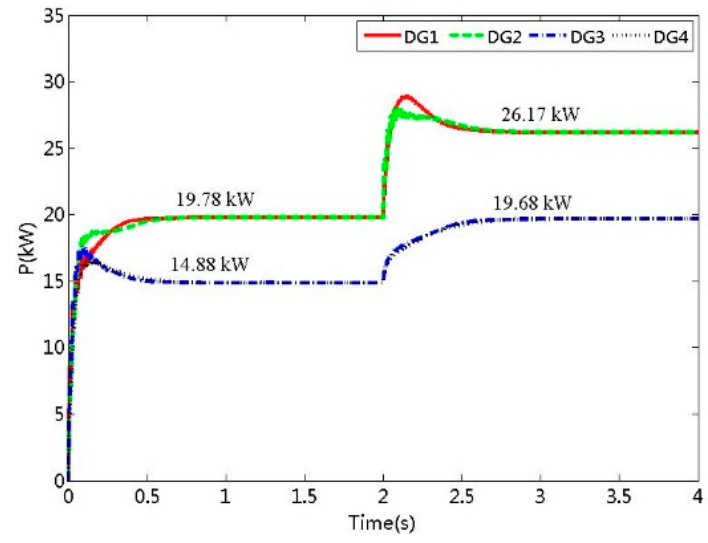

(b)

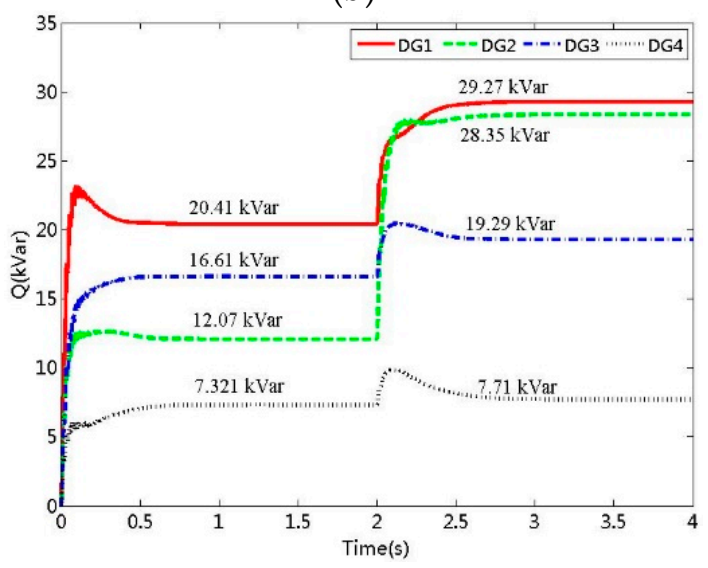

(d)

Figure 9. Cont. 


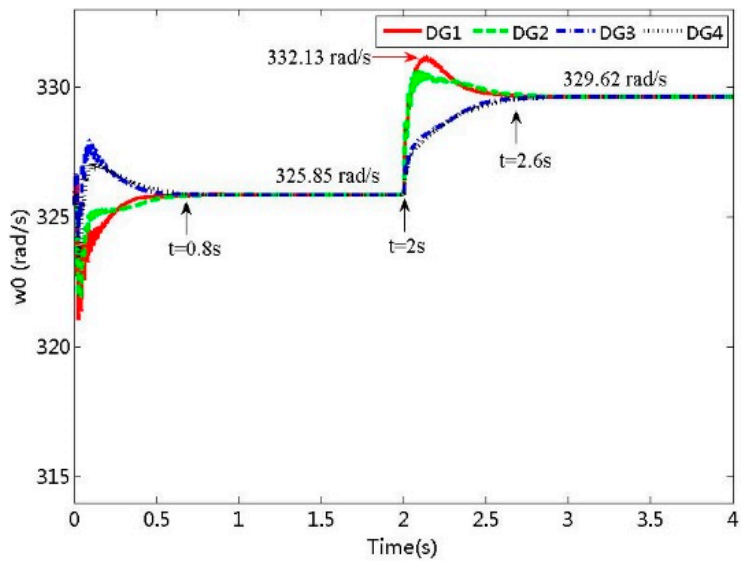

(e)

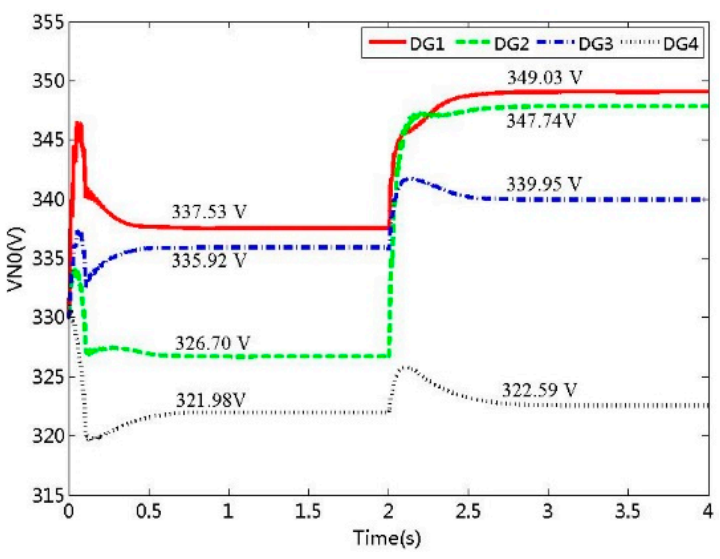

(f)

Figure 9. Simulation results without time-delays and disturbance. (a) Frequency; (b) active power of each DG; (c) voltage; (d) reactive power of each DG; (e) adaptive $\omega_{o i} ;(\mathbf{f})$ adaptive $V_{o i}$.

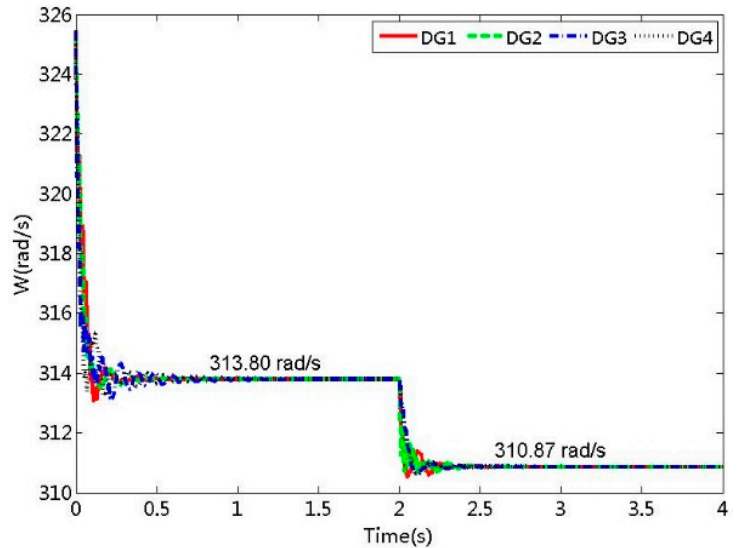

(a)

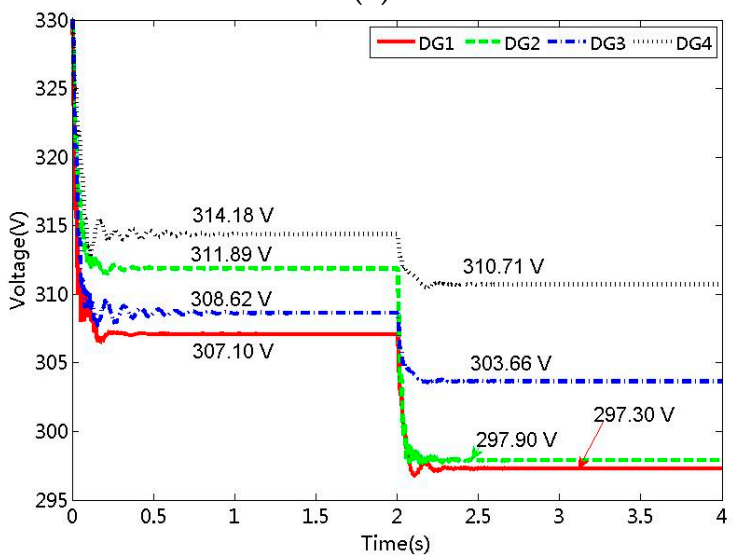

(c)

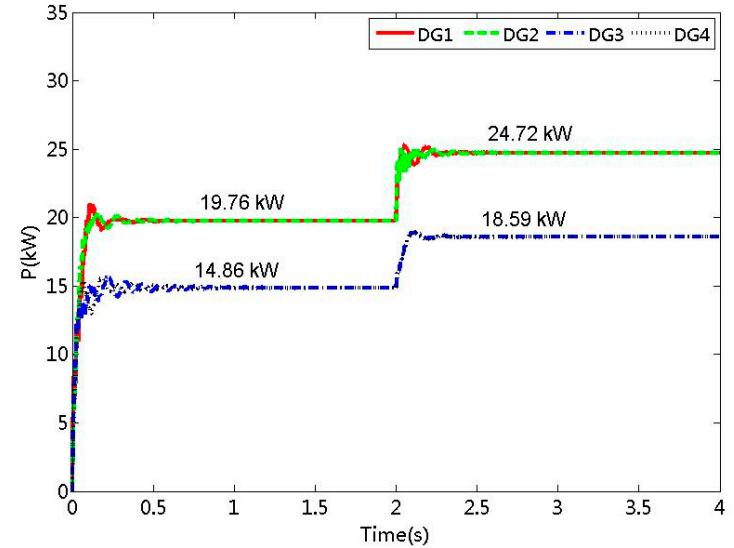

(b)

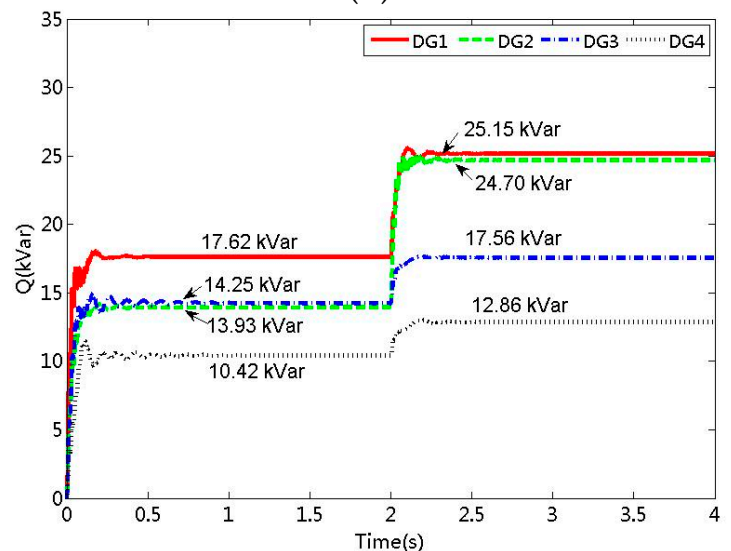

(d)

Figure 10. Simulation results with the traditional droop control. (a) Frequency; (b) active power of each DG; (c) voltage; $(\mathbf{d})$ reactive power of each DG.

\subsection{Case Study II: Simulation with Time-Delays}

This case investigates the performance when the time-delays in communication network are taken into consideration. In the simulation, the time-delays at each edge of the graph is set as $0.5 \mathrm{~s}$, and Load 2 connects to the grid at $t=10 \mathrm{~s}$. The simulation results are illustrated in Figure 11. 


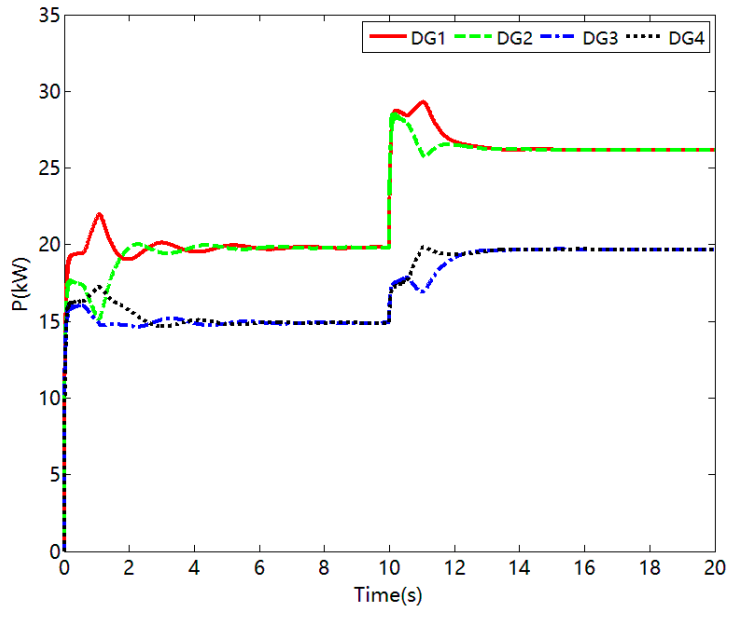

(a)

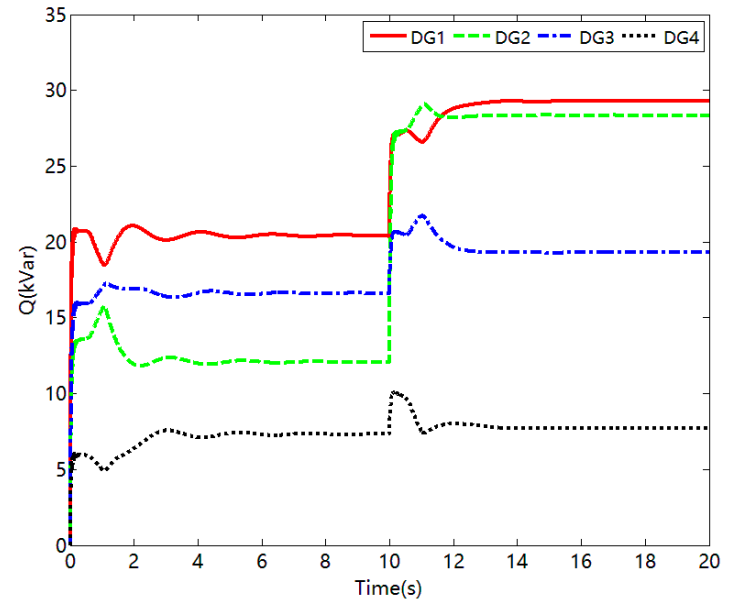

(b)

Figure 11. Simulation results with time-delays. (a) Active power; (b) reactive power.

\subsection{Case Study 3: Simulation with Time-Delays and Disturbance}

In this case, both the time-delays and disturbance are considered in communication network to verify the effectiveness of the proposed control. In this simulation case, the high frequency disturbing signals are injected into the received information from $D G_{j}$ to $D G_{i}$, where $\delta_{\omega j}=1.25 \sin (2 \pi 500 t)$ and $\delta_{P j}=50 \sin (2 \pi 500 t)$ are the disturbances for frequency and active power, respectively. The time-delays is also $0.5 \mathrm{~s}$. The simulation results are illustrated in Figure 12.

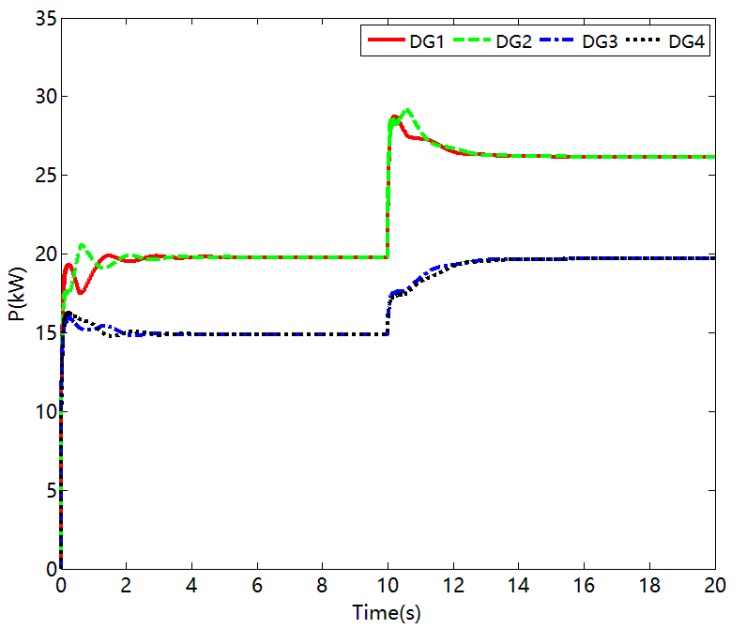

(a)

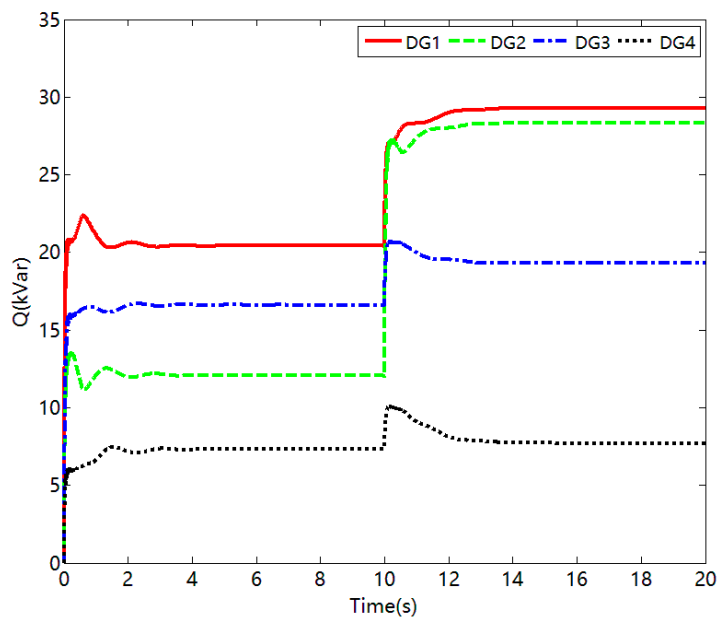

(b)

Figure 12. Simulation results with time-delays and disturbances. (a) Active power; (b) reactive power.

\section{Analysis and Discussion}

As shown in Figure 9e, $\omega_{o i}$ changes along with the loads under the synergetic control. As a result, the system frequency is always at the rated $(314.16 \mathrm{rad} / \mathrm{s})$ with little disturbance, as shown in Figure 9a. However, in Figure 10a, although the initial stable frequency has been regulated around the rated value by setting $\omega_{o i}$, it drops to $310.87 \mathrm{rad} / \mathrm{s}$ when $\operatorname{Load}_{2}$ connects to the grid at $t=2 \mathrm{~s}$ due to the constant value of $\omega_{o i}$. Meanwhile, in Figure 9a, we know that all DGs work to the expected frequency after a regulation time of about $0.6 \mathrm{~s}$. Therefore, the synergetic control can keep the system frequency near the expected value, and prevent the disturbances while the loads change. At the same time, the active power allocation among DGs is in inverse proportion to the droop coefficients under 
the operation of synergetic control without leaders, which is the same with that in traditional droop control, as illustrated in Figures 9b and 10b.

In Figure 9c, the amplitude voltage of each DG is the rated value at the initial stable state under the proposed voltage control, while it varies from 307 to $314 \mathrm{~V}$ in traditional droop control, as illustrated in Figure 10c. In particular, the output voltages of DG drops a lot in traditional droop control when Load2 connects to the system, while they can be kept at the rated value in the proposed control because of the adaptive regulation of $V_{0 i}$, as shown in Figure 9f. The simulation results show that the voltage amplitude of DG can be kept stable at the expected value regardless of the disturbance of loads under the proposed voltage control. As a result, the active and reactive power under the proposed control is higher than that in traditional control because: (1) the loss of active power increases in transmission lines; and (2) the increased reactive power is used to compensate the voltage droop by line inductance, as shown in Figure 9b,d and Figure 10b,d. Meanwhile, since the voltage of DG is always around the expected and the reactive power flow is allocated locally, the output reactive power that is close to the loads is larger than the remote one. Correspondingly, in Figure 9d, the reactive power of DG2 increases more than others.

From Figure 12, we can see that the MG can work at a stable state in spite of the impacts of disturbances, in which the active and reactive power of each DG is the same with that without disturbance. Thus, the proposed adaptive droop works properly under the case with time-delays and disturbances. However, the control time increases to $4 \mathrm{~s}$, which is $0.6 \mathrm{~s}$ in the case without time-delays and disturbances and $3 \mathrm{~s}$ in the case that there is only time-delays.

During the period of $10 \mathrm{~s} \sim 10.5 \mathrm{~s}$, the active and reactive power of DG are allocated in inverse proportion to the droop coefficients because that the information received from the neighbors is not updated in time. After the time-delays, the synergetic control in Equations (13), (22) and (31) works to control the frequency and voltage to be the expected value, and the system works at a new stable state after about $2.5 \mathrm{~s}$. The simulation results indicate that the proposed control strategy has a good performance despite of the time-delays in communication. By comparing the simulation results in $\mathrm{s} 9$ and 11, we can see that the control time is much longer than that without time-delays.

To verify the effectiveness of the adaptive control strategy, the comparisons with the improved or adaptive droop control in $[17,21,22,24]$ are done, and the results are shown in Table 3. In [17] and [22], the power angle-active power droop is used instead of the frequency-active power control, the frequency error is eliminated consequently. Moreover, the system in [17] is stable due to the utilization of a stabilizer, but the voltage error still exists. Although the nonlinear droop control in [21] has a good system stability performance, the active power allocation is not proportional to its rated value. The adaptive virtual impedance in [24] can enhance the reactive power allocation among DGs, but the system may be unstable and the frequency and voltage errors are not eliminated.

Table 3. Comparison with the improved control methods.

\begin{tabular}{cccccc}
\hline $\begin{array}{c}\text { Control Strategy } \\
\text { [Reference] }\end{array}$ & Communication & $\begin{array}{c}\text { Frequency } \\
\text { Error }\end{array}$ & $\begin{array}{c}\text { Voltage } \\
\text { Error }\end{array}$ & $\begin{array}{c}\text { System } \\
\text { Stability }\end{array}$ & Active Power Allocation \\
\hline Synergetic control & necessary & No & No & stable & proportional to the rated \\
\hline$[17]$ & unnecessary & No & Yes & stable & proportional to the rated \\
\hline$[21]$ & unnecessary & Yes & Yes & stable & nonlinear with the frequency \\
\hline$[22]$ & unnecessary & No & Yes & SSS & proportional to the rated \\
\hline$[24]$ & unnecessary & Yes & Yes & SSS & proportional to the rated \\
\hline
\end{tabular}

\section{Conclusions}

Distributed control of islanded MGs makes the system more reliable because the central controller and the complex communication network are avoided. In this paper, distributed control based on MAS is adopted to adaptively design the droop parameters. The concept of a general control algorithm 
considering time-delays in communication network is proposed in this paper. In the proposed control, the DG regulates its output power to work at an expected state by setting the auxiliary variable with the power and voltage of the neighbors and itself. Because the output active power of DG changes along with the loads and cannot be obtained at the beginning, the synergetic control without leaders is used to design the auxiliary variable in active power allocation. Meanwhile, the synergetic control with a virtual leader is proposed to design the auxiliary variables in order to control the system frequency and voltage at the expected. The MG system has the globally asymptotical stability under the synergetic control, which has been proved by the direct Lyapunov method. Moreover, the impacts of and disturbance on control precision and system stability are discussed. Simulation results have also verified the effectiveness.

Acknowledgments: This work was supported by the National Natural Science Foundation of China (No. 51577115) and the National Science and Technology Major Project (No. 2016YFB0901304).

Author Contributions: All the authors contributed to this work. Zhiwen Yu designed the study, performed the analysis, performed simulations, and wrote the first draft of the paper. Qian Ai set the simulation environment, and checked the overall logic of this work. Xing He and Longiian Piao contributed to providing important comments on the modeling and thoroughly revised the paper.

Conflicts of Interest: The authors declare no conflict of interest.

\section{Abbreviations}

$P_{L} \quad$ the active power in the transmission line

$Q_{L} \quad$ the reactive power in the transmission line

$P_{i} \quad$ the active power of $D G_{i}$

$Q_{i} \quad$ the reactive power of $D G_{i}$

$V \quad$ amplitude voltage of the node

$\delta \quad$ voltage phase of the node

$R \quad$ resistance of the transmission line

$X \quad$ reactance of the transmission line

$\Delta \delta \quad$ power angle

$\Delta V \quad$ voltage drop

$\omega_{i} \quad$ frequency of $D G_{i}$

$V_{d i}^{*} \quad$ amplitude voltage in $d$-axis

$V_{q i}^{*} \quad$ amplitude voltage in $q$-axis

$\omega_{0 i} \quad$ frequency when the active power is zero

$V_{0 i} \quad$ voltage when there active power is zero

$m_{i} \quad$ droop coefficient in active power control

$n_{i} \quad$ droop coefficient in reactive power control

$x_{\omega} \quad$ frequency first derivative in $\mathrm{Rad} / \mathrm{s}$

$x_{v} \quad$ voltage first derivative in $\mathrm{V} / \mathrm{s}$

$x_{P} \quad$ active power first derivative in $\mathrm{W} / \mathrm{s}$

$u_{c \omega i} \quad$ control variables in frequency control

$u_{c v i} \quad$ control variables in voltage control

$u_{c P i} \quad$ control variables in active power control

$t_{d} \quad$ time-delays in communication

$k_{P 1}, k_{p 2} \quad$ control gains in active power control

$k_{\omega 1}, k_{\omega 2}, k_{\omega 3}$ control gains in frequency control

$k_{v 1}, k_{v 2}, k_{v 3} \quad$ control gains in voltage control

\section{References}

1. Erseghe, T.; Tomasin, S. Power flow optimization for smart microgrids by SDP relaxation on linear networks. IEEE Trans. Smart Grid 2013, 4, 751-762. [CrossRef]

2. Ahn, S.-J.; Nam, S.-R.; Choi, J.-H.; Moon, S.-I. Power scheduling of distributed generators for economic and stable operation of a microgrid. IEEE Trans. Smart Grid 2013, 4, 398-405. [CrossRef]

3. Su, X.; Han, M.; Guerrero, J.; Sun, H. Microgrid Stability Controller Based on Adaptive Robust Total SMC. Energies 2015, 8, 1784-1801. [CrossRef] 
4. Pourmousavi, S.A.; Nehrir, M.H.; Colson, C.M.; Wang, C. Real-time energy management of a stand-alone hybrid wind-microturbine energy system using particle swarm optimization. IEEE Trans. Sustain. Energy 2010, 1, 193-201. [CrossRef]

5. Wang, W.; Zeng, X.; Tang, X.; Tang, C. Analysis of microgrid inverter droop controller with virtual output impedance under non-linear load condition. IET Power Electron. 2014, 7, 1547-1556. [CrossRef]

6. Arul, P.G.; Ramachandaramurthy, V.K.; Rajkumar, R.K. Control strategies for a hybrid renewable energy system: A review. Renew. Sustain. Energy Rev. 2015, 42, 597-608. [CrossRef]

7. Majumder, R.; Ledwich, G.; Ghosh, A.; Chakrabarti, S.; Zare, F. Droop control of converter-interfaced microsources in rural distributed generation. IEEE Trans. Power Deliv. 2010, 25, 2768-2778. [CrossRef]

8. Yao, W.; Chen, M.; Matas, J.; Guerrero, J.M.; Qian, Z.-M. Design and analysis of the droop control method for parallel inverters considering the impact of the complex impedance on the power sharing. IEEE Trans. Ind. Appl. 2011, 58, 576-588. [CrossRef]

9. Balaguer, I.J.; Lei, Q.; Yang, S.; Supatti, U.; Peng, F.Z. Control for grid-connected and intentional islanding operations of distributed power generation. IEEE Trans. Ind. Appl. 2011, 58, 147-157. [CrossRef]

10. Pogaku, N.; Prodanovic, M.; Green, T.C. Modeling, analysis and testing of autonomous operation of an inverter-based microgrid. IEEE Trans. Power Electron. 2007, 22, 613-625. [CrossRef]

11. Abdelaziz, M.M.A.; Farag, H.E.; El-Saadany, E.F. Optimum droop parameter settings of islanded microgrids with renewable energy resources. IEEE Trans. Sustain. Energy 2014, 5, 434-445. [CrossRef]

12. Barklund, E.; Pogaku, N.; Prodanovic, M.; Hernandez-Aramburo, C.; Green, T.C. Energy management in autonomous microgrid using stability-constrained droop control of inverters. IEEE Trans. Power Electron. 2008, 23, 2346-2352. [CrossRef]

13. Diaz, G.; Gonzalez-Moran, C.; Gomez-Aleixandre, J.; Diez, A. Scheduling of droop coefficients for frequency and voltage regulation in isolated microgrids. IEEE Trans. Power Syst. 2010, 25, 489-496. [CrossRef]

14. Kim, J.; Guerrero, J.M.; Rodriguez, P.; Teodorescu, R.; Nam, K. Mode adaptive droop control with virtual output impedances for an inverter-based flexible AC microgrid. IEEE Trans. Power Electron. 2011, 26, 689-701. [CrossRef]

15. He, J.; Li, Y.W. Analysis, design, and implementation of virtual impedance for power electronics interfaced distributed generation. IEEE Trans. Ind. Appl. 2001, 47, 2525-2538. [CrossRef]

16. Azadani, E.N.; Hosseinian, S.H.; Divshali, P.H.; Vahidi, B. Stability constrained optimal power flow in deregulated power systems. Electr. Power. Compon. Syst. 2011, 39, 713-732. [CrossRef]

17. Majumder, R.; Chaudhuri, B.; Ghosh, A.; Majumder, R.; Ledwich, G.; Zare, F. Improvement of stability and load sharing in an autonomous microgrid using supplementary droop control loop. IEEE Trans. Power Syst. 2010, 25, 796-808. [CrossRef]

18. Divshali, P.H.; Hosseinian, S.H.; Azadani, E.N.; Abedi, M. Application of bifurcation theory in dynamic security constrained optimal dispatch in deregulated power system. Electr. Eng. 2011, 93, 157-166. [CrossRef]

19. Divshali, P.H.; Hosseinian, S.H.; Abedi, M. A novel multi-stage fuel cost minimization in a VSC-based microgrid considering stability, frequency and voltage constraint. IEEE Trans. Power Syst. 2013, 28, 931-939. [CrossRef]

20. Vasquez, J.C.; Guerrero, J.M.; Luna, A.; Rodriguez, P.; Teodorescu, R. Adaptive droop control applied to voltage-source inverters operating in grid-connected and islanded modes. IEEE Trans. Ind. Appl. 2009, 56, 4088-4096. [CrossRef]

21. Rowe, C.N.; Summers, T.J.; Betz, R.E.; Cornforth, D.J.; Moore, T.G. Arctan power-frequency droop for improved microgrid stability. IEEE Trans. Power Electron. 2013, 28, 3747-3759. [CrossRef]

22. Hu, J.; Zhu, J.; Dorrell, D.G.; Guerrero, J.M. Virtual flux droop method-A new control strategy of inverters in microgrids. IEEE Trans. Power Electron. 2014, 29, 4704-4711. [CrossRef]

23. Golsorkhi, M.S.; Lu, D.D.C.; Guerrero, J.M. A GPS-Based Decentralized Control Method for Islanded Microgrids. IEEE Trans. Power Electron. 2017, 32, 1615-1625. [CrossRef]

24. Zhu, Y.; Zhuo, F.; Wang, F.; Liu, B.; Zhao, Y. A Wireless Load Sharing Strategy for Islanded Microgrid Based on Feeder Current Sensing. IEEE Trans. Power Electron. 2015, 30, 6706-6719. [CrossRef]

25. Behjati, H.; Davoudi, A. Reference-change response assignment for pulse-width-modulated dc-dc converters. IET Power Electron. 2014, 7, 1414-1423. [CrossRef]

26. Jiang, Z.; Dougal, R.A. Synergetic control of power converters for pulse current charging of advanced batteries from a fuel cell power source. IEEE Trans. Power Electron. 2004, 19, 1140-1150. [CrossRef] 
27. Bidram, A.; Davoudi, A.; Lewis, F.L.; Guerrero, J.M. Distributed cooperative secondary control of microgrids using feedback linearization. IEEE Trans. Power Syst. 2013, 28, 3462-3470. [CrossRef]

28. Bidram, A.; Davoudi, A.; Lewis, F.L.; Qu, Z. Secondary control of microgrids based on distributed cooperative control of multi-agent system. IET Gener. Transm. Distrib. 2013, 7, 822-831. [CrossRef]

29. Yu, Z.; Ai, Q.; Gong, J.; Piao, L. A novel secondary control for microgrid based on synergetic control of multi-agent system. Energies 2016, 9, 243. [CrossRef]

30. Wang, Z.; Wu, W.; Zhang, B. A fully distributed power dispatch method for fast frequency recovery and minimal generation cost in autonomous microgrids. IEEE Trans. Smart Grid 2016, 7, 19-31. [CrossRef]

31. Shuai, Z.; Sun, Y.; Shen, Z.J.; Tian, W.; Tu, C.; Li, Y.; Yin, X. Microgrid stability: Classification and a review. Renew. Sustain. Energy Rev. 2016, 58, 167. [CrossRef]

32. Komurcugil, H.; Altin, N.; Ozdemir, S.; Sefa, I. An extended lyapunov-function-based control strategy for single-phase UPS inverters. IEEE Trans. Power Electron. 2015, 30, 3976-3983. [CrossRef]

33. Lopez-Martinez, M.; Delvenne, J.C.; Blonde, V.D. Optimal sampling time for consensus in time-delayed networked systems. IET Control Theory Appl. 2012, 6, 2467-2476. [CrossRef]

(C) 2016 by the authors; licensee MDPI, Basel, Switzerland. This article is an open access article distributed under the terms and conditions of the Creative Commons Attribution (CC-BY) license (http://creativecommons.org/licenses/by/4.0/). 